\title{
A BASE NACIONAL CURRICULAR COMUM: UM DIÁLOGO COM ELIZABETH MACEDO ${ }^{i}$
}

\section{LA BASE CURRICULAR NACIONAL COMÚN: UN DIÁLOGO CON ELIZABETH}

MACEDO

THE COMMON NATIONAL CURRICULAR BASE: A DIALOGUE WITH ELIZABETH MACEDO

DOI: $10.22481 /$ rbba.v1i02.7790

Maria Santos

Universidade do Estado do Rio de Janeiro, Brasil

ORCID: https://orcid.org/0000-0001-9297-4539

Lattes: http://lattes.cnpq.br/0699554024690160

Endereço eletrônico: santtosmaria.m@gmail.com

\section{RESUMO}

Esse escrito busca resenhar o pensamento de Elizabeth Macedo em textos referentes a Base Nacional Comum Curricular (BNCC). Nele irei tecer interpretações sobre os seguintes textos: 1) "Base nacional curricular comum: novas formas de sociabilidade produzindo sentidos para educação", (MACEDO, 2014); 2) "Base nacional curricular comum: a falsa oposição entre conhecimento para fazer algo e conhecimento em si", (MACEDO, 2016); 3) "As demandas conservadoras do movimento escola sem partido e a Base Nacional Curricular Comum”, (MACEDO, 2017); 4) “"A base é a base'. E o currículo o que é?", (MACEDO, 2018); e 5) "Fazendo a base virar realidade: competências e o germe da comparação", (MACEDO, 2019). O que busco a partir do pensamento de Macedo, é situar os agentes políticos que têm atuado na tentativa de hegemonização de uma base sobre o pretexto de mais qualidade na educação e justiça social. O ponto central é pensar, já que a base foi implementada, seus sentidos, e como os escritos da 
pesquisadora foram se desdobrando entre os anos de 2014 a 2019 na tentativa de apresentar os significantes à BNCC.

Palavras-chave: Base Nacional Comum Curricular; Diálogo; Significantes; Elizabeth Macedo.

\title{
RESUMEN
}

Este texto busca hacer una reseña del pensamiento de Elizabeth Macedo en textos referentes a la Base Nacional Común Curricular (BNCC). En él iré hacer interpretaciones sobre los siguientes textos: 1) "Base nacional común curricular: nuevas formas de sociabilidad que producen significados para la educación", (MACEDO, 2014); 2) "Base nacional común curricular: la falsa oposición entre el conocimiento para hacer algo y el conocimiento en si mismo", (MACEDO, 2016); 3) "Las demandas conservadoras del movimiento escuela sin partido y la base nacional común curricular", (MACEDO, 2017); 4) "'La base es la base'. ¿Y qué es el currículum?”, (MACEDO, 2018); y 5) "Haciendo la base tornarse realidad: las competencias y el germen de la comparación", (MACEDO, 2019). Lo que busco a partir del pensamiento de Macedo es situar a los agentes políticos que vienen trabajando en el intento de hegemonizar una base con el pretexto de más calidad en la educación y justicia social. El punto central es pensar, desde que se implementó la base, sus significados, y cómo se fueron desarrollando los escritos de la investigadora entre los años 2014 a 2019 en un intento de presentar los significantes a la BNCC.

Palabras clave: Base Nacional Común Curricular; Diálogo; Significantes; Elizabeth Macedo.

\begin{abstract}
This writing seeks to describle the thought Elizabeth Macedo in texts referrings to the National Curriculum Common Core (BNCC). In it I will weave interpretations on the following texts: 1) "National Curriculum Common Core: new forms of sociability producing meanings for education", (MACEDO, 2014); 2) " National Curriculum Common Core: the false opposition between knowledge to do something and knowledge itself", (MACEDO, 2016); 3) "The conservative demands of the partyless school movement and the National Curriculum Common Core", (MACEDO, 2017); 4) "“The base is the base'. And what is the curriculum?", (MACEDO, 2018); e 5) "Making the basis become reality: competence and the germ of comparison", (MACEDO, 2019). What I seek starting in the thinking Macedo, it is to situate the political agents that have acted in the attempt to hegemonization of a base on the pretext of more quality in education and social justice. The central point is to think, since the base has been implemented, her senses, and
\end{abstract}


MACEDO

how the researcher's writings unfolded between the years 2014 to 2019 in an attempt to present the signifiers to the BNCC.

Keywords: National Curriculum Common Core; Dialogue; Significant; Elizabeth Macedo.

\section{Um rastro inicial de escrita}

Elizabeth Macedo em diversos dos seus textos vêm tentando responder à pergunta sobre o que seja a Base Nacional Curricular Comum (BNCC). Ela nos situa de que a discussão no Brasil não é algo novo e que os sentidos atribuídos ao termo Base precisariam retomar aos anos de 1980, se fossemos assumir uma definição ampla para ela. Nas palavras dela, "talvez pudéssemos dizer que, ao ser promulgada em 1996, a LDB pós-ditadura consolidou uma demanda já existente por uma” (MACEDO, 2014, p. 1532). A sua defesa, em seus escritos, é que implementação do documento segue uma normatização, e questiona a ausência de pensamento curricular a base: ““A base é a base'. E o currículo o que é?”, (MACEDO, 2018, p. 28). Muitas inquietações são apresentadas em seus textos, e a sua posição é sempre contrária a uma base em razão de que ela age em uma perspectiva de maior controle dos currículos. Por esse razão, esse escrito busca interpretar o pensamento de Macedo nos textos 1) "Base nacional curricular comum: novas formas de sociabilidade produzindo sentidos para educação", (MACEDO, 2014); 2) "Base nacional curricular comum: a falsa oposição entre conhecimento para fazer algo e conhecimento em si”, (MACEDO, 2016); 3) “As demandas conservadoras do movimento escola sem partido e a base nacional curricular comum”, (MACEDO, 2017); 4) “"A base é a base'. E o currículo o que é?”, (MACEDO, 2018); e 5) "Fazendo a base virar realidade: competências e o germe da comparação", (MACEDO, 2019). Neles é possível situar os agentes políticos que têm atuado na tentativa de hegemonização de uma base sobre o pretexto de mais qualidade na educação e justiça social. O ponto central é pensar, já que ela foi implementada, seus sentidos, e como os escritos de Elizabeth Macedo foram se desdobrando entre os anos de 2014 a 2019, na tentativa de apresentar os significantes nela engendrados. Por isso, este texto exige não os nomear, separadamente, em seções, e sim, provocar um movimento de diálogo entre eles, que se misturam a ideias de outros escritos de pesquisadores e teóricos. 
MACEDO

\section{E então, é possível nomear a base?}

No primeiro texto que trago, Base nacional curricular comum: novas formas de sociabilidade produzindo sentidos para educação, Macedo (2014), identifica os agentes políticos que vem atuando na consolidação da base apoiada no conceito de redes políticas de Stephen Ball, e a teoria do discurso de Ernesto Lacou. Argumenta que pós-ditadura, com a promulgação da LDB 9.394/96, consolidou nela, menções políticas a uma base comum, sendo que essas menções se associaram as diretrizes curriculares nacionais. Aqui o termo competência já passa a integrar a ideia de base, chamando a atenção da sua existência em outros documentos políticos. Ela apresenta os Parâmetros Curriculares Nacionais (PCN), primeira tentativa de uma base, como contexto histórico de 'solução razoável' (MACEDO, 2014, p. 1533), que seguia característica de países da Europa e Estados Unidos, e propostas do Banco Mundial; além de matrizes de referência para avaliação. Os anos que marcaram tais movimentos, eram os de 1970 a 1990, onde a tentativa de padronização curricular surgia como algo forte no Brasil, em que agentes públicos e privados apareciam, e ainda aparecem, para interferir nas políticas de currículo, o que pensando com Brown (2017), trata-se de uma tentativa de economização da vida pública.

Se interpretado dessa forma, padronizar o currículo vai para além da discussão curricular. Ela adentra na padronização da vida pública dos sujeitos. Por isso, Macedo apresenta agentes financeiros que vêm interessados nessa economização em nome da produção de mais educação, a saber: "Roberto Marinho, Victor Civita, Airton Senna e Lemann, empresas como Natura, Gerdau e Volkswagen, grupos educacionais como CENPEC e "movimentos" como Todos pela Educação" (MACEDO, 2014, p. 1533); além de "sujeitos políticos "públicos" envolvidos nas políticas em curso: MEC, CNE, CONSED, UNDIME”, (MACEDO, 2014, p. 1533). É a 'marca' de como as políticas neoliberais borram as políticas de currículo. Ao meu ver, o texto propõe o início de pensamento de como as políticas neoliberais foram ganhando forças nas políticas curriculares, considerando que elas foram 'nascendo' juntamente no Brasil, com o neoliberalismo, que tornou-se mais 'visível' com a entrada do presidente da república Fernando Henrique Cardoso [1995-2002].

Nesse texto ainda é possível localizar as demandas por centralização das políticas, dos PCN à BNCC, em que a sua defesa para significar essas políticas, atravessa um lugar impossível pelo discurso hegemônico, pois "a hegemonia nunca será dada”, (MACEDO, 2014, p. 1535- 

MACEDO

1536). Por ser impossível, é o que faz articulações produzirem a retórica de mais qualidade e mais educação, como um 'lugar' de fantasia da crise do sistema educacional. O que pode parecer oposição a qualidade, na verdade é uma luta não unitária, pois "elas são constituídas e hegemonizadas em outras articulações”, (MACEDO, 2014, p. 1536). Se é o discurso de qualidade da educação que marca a consolidação da BNCC, não pode haver garantias, pois pensando com Lopes (2015, p. 131), qualquer tentativa de fazê-la "é capaz de bloquear efeitos críticos e democráticos". Para Hypolito (2019), a ideia de produzir mais educação nada mais é do que um discurso mercadológico, de controle a partir de melhores índices de qualidade de ensino medidos por avaliações nacionais, cuja definição Macedo (2014) vem concordar, sobretudo quando apresenta experiência de outros países em seus textos, sobre testagens e currículo comum.

O que parece ser ainda interessante no texto, é como as redes políticas nacionais e internacionais se cruzam, só que sem fechamentos de pontos para a própria política e o currículo. Ela usa Ball para apresentar essas redes e como atores públicos e privados estão participando das políticas curriculares com novas formas de governamentabilidade. Para Foucault (2008, p. 310), essas novas formas de governar é "uma concepção de força de trabalho, é uma concepção do capital-competência", e em razão disso, minha questão é: como continuar o debate da BNCC, haja vista que ela já está aqui para nós como força de trabalho, mesmo apresentando oposição a ela? Como nós, agentes da vida pública, podemos caminhar na contramão da BNCC? Me parece que para significá-la, agora, seja preciso sair da ideia de um universal e este é o contive de Macedo, mesmo que para sair desse universal, seja também preciso pensar o controle da qualidade, e do que será ensinado e aprendido. E para além disso, repensar o que estamos pensando sobre o neoliberalismo nas políticas de currículo e formas de governar, que como ela coloca ao final do seu texto, "prometendo a felicidade irracional", (p. MACEDO, 2014, 1553).

No texto Base nacional curricular comum: a falsa oposição entre conhecimento para fazer algo e conhecimento em si, Macedo (2016) segue defendendo que o debate sobre a base assume uma pluralidade de demandas. Toma a experiência da Austrália para colocar ideias que se antagonizaram no Brasil na busca por implementação, qual seja, a oposição entre conhecimento para fazer algo e conhecimento em si. Com isso, busca localizar a retórica de maior acesso, equidade e resultados educacionais por meio de um currículo comum. Seus argumentos, se mantêm apoiados na teoria do discurso de Laclau e Mouffe, seguindo a \begin{tabular}{l|l} 
Revista RBBA & Revista Binacional Brasil Argentina
\end{tabular} 

MACEDO

afirmativa de que há no processo de significação, fixação ao controle do currículo que vem se esvaziando ao longo das últimas quatro décadas. Se no texto anterior (MACEDO, 2014), tentava apresentar os agentes políticos para o processo de hegemonização, nesse texto, localiza os movimentos que têm produzido demandas a um currículo comum, como o Plano Nacional de Educação.

Contudo, foco na experiência australiana, que para mim, trata-se de justificar que intervenções no currículo com base na ideia do comum, e do argumento de mais educação, justiça social e igualdade democrática, não é algo simples. Perguntas como, o que é um currículo comum, e quem pode definir esse algo comum, precisam ser novamente elaboradas, haja visto que, quando o texto foi construído não havia uma versão final sobre as bases comuns do ensino fundamental e médio. Para respondê-las considero que não se pode deixar de fora dois pontos: 1) a falsa ideia que circula entorno delas, que é diminuição das desigualdades sociais; 2) situar qual o lugar do conhecimento na ideia de algo comum. Para Brown (2017), usar o discurso da diminuição da desigualdade sociais nas políticas, é um dos motores que sustenta o neoliberalismo, que sempre aparece ou fala em nome de outros, o que acentua na visão de Price (2014), que mais reforma, denota menos mudança, por deixar de fora muitas vozes em nome de uma competência. É talvez por essa razão que Macedo (2016) tenta diferenciar o conhecimento de si (prevalência dos campos disciplinares - campos científicos) e o conhecimento para fazer algo (aprender a aprender), que tem acompanhado as discussões da Base. Uma promessa de ilusão como ela coloca, que disputa signifiXação.

É entorno dessa signifiXação que a ação política da base se borra, já que uma política totalmente igualitária é impossível de realizar ou jamais será cumprida, uma vez que "ela justifica a intervenção que não produz nem os resultados prometidos nem aqueles que podemos almejar de forma responsável”, (MACEDO, 2016, p. 63). No que diz respeito ao conhecimento de si e para fazer algo, acabam atuando como um valor de troca (economia), que a cada dia foge a mão do controle, pelo próprio crescimento do capitalismo. Então, como (ainda que considerando impossível), controlar o conhecimento de si e o conhecimento para fazer algo? A aposta seria sair do controle e investir na ideia de que é preciso educar ao invés de ensinar (MACEDO, 2017). Inclusive para demandas conservadoras que deslocaram a negociação da base, como a Escola sem Partido.

Pensando nisso, trago ao debate o texto As demandas conservadoras do movimento escola sem partido e a base nacional curricular comum, em que Macedo (2017a), defende que \begin{tabular}{l|l} 
Revista RBBA & Revista Binacional Brasil Argentina
\end{tabular} 

MACEDO

na luta por significação as demandas aparecem de forma diferentes para cada grupo/ator social. O que ela busca é interpretar como as negociações políticas em curso a elaboração da base são negociadas com a entrada de um outro agente, a Escola Sem Partido. Embora não seja seu foco o que levou a criação do projeto, é importante situar que ele surgiu em 2004 reunindo defensores que se dizem contrários a "doutrinação ideológica” nas escolas de nível básico e superior. É com esse dado que Macedo vem propondo uma discussão de sentidos dos direitos públicos apreendidos pelo discurso neoliberal em que forças políticas tencionam os acordos para uma BNCC de "funcionamento de uma normatividade neoliberal", (MACEDO, 2017a, p. 509), e sustenta com base nessa afirmativa, que "o compromisso com a defesa de que educação e currículo estão diretamente imbricados com a diferença" (MACEDO, 2017a, p. 510), essa que pensando com Derrida (1995, p. 65) "cada outro é cada outro".

Os significantes que nucleiam a discussão desse texto, apoiada na teoria do discurso de Laclau, são o "neoliberal por accountability” e "crítica por justiça social”, (MACEDO, 2017a, p. 510). Neles significantes como equidade, igualdade, prestação de contas, reponsabilidade, oportunidades são os pilares que sustentam a articulação de demandas como raça e sexualidade, e a busca de preencher sentidos a BNCC. Ao expor isso, a questão do direito a aprendizagem e ensino condessam uma expectativa de mais aprendizagem, que no meu modo de pensar se difere de mais educação. Em um outro texto, Macedo (2015) ao colocar a questão da aprendizagem, apresenta como uma performance medida pelo Estado, e acrescenta que, na formulação do direito a aprendizagem, há "um conjunto de ações que não pode ser garantidas pela escola ou por qualquer outro agente externo", (MACEDO, 2015, p. 896). Assim, na análise das versões da BNCC, $1^{\text {a }}$ e $2^{\mathrm{a}}$ versão, e a já implementada, o direito passou a ser algo central, onde a ideia de justiça social aparece como sustento ao direito a aprendizagem. O que me chama atenção é como o direito marca a cobrança de mais garantias para estudantes. Ao colocar isso, não afirmo que sou contra os direitos ou a justiça social, só que elas acontecem de maneira diferente para todos, inclusive quando grupos de pessoas saem nas ruas reivindicando novos direitos ao estado.

Butler (2018) faz uma questão pertinente que cabe a discussão: o que pode um corpo na rua? Esse corpo que como povo não é uma unidade, que reunido em assembleia como outros corpos, mobiliza o estado a olhar para as demandas, essas que são sempre diferentes. Por isso, esse direito não garante, mas enquadra o sujeito a reivindicar seus direitos onde a diferença na medida que aparece, desaparece. Contudo, no campo do currículo, como elenca Macedo 

MACEDO

(2017a), estamos marcados por tradição técnica de produção e representação, e no jogo político "entre demandas críticas por justiça social e demandas neoliberais por accountability explicita afastamentos e aproximações entre elas”, (MACEDO, 2017a, p. 514). Assim, no que diz respeito a entrada do projeto Escola sem Partido na BNCC, passou a ganhar visibilidade após impeachment de Dilma, em que forças conservadoras passaram a questionar os conteúdos a serem ensinados a partir da ordem do direito. No entanto, se o direito age sob a justiça, e ela só seria justa se operasse por ela mesma, como forças conservadoras apoiam-se no direito? Faço essa questão amparada na leitura de Derrida (1995), porque aposto ser preciso trazer a imensa história de responsabilidade do Estado nas políticas de currículo. No entanto, é aqui que se antes a BNCC não era um currículo, passou a ser nomeado por esses agentes, em que as garantias do que ensinar deveriam ser determinadas pelo parlamento, inclusive a defesa do direito para as famílias educarem seus filhos em casa - home school.

Essa reivindicação nas palavras de Macedo (2017a, p. 515) "pouco tem deslocado as relações de poder até então estabelecidas no que tange às formas de significar a base curricular comum em nível nacional”, isto porque os agentes públicos e privados defendem fortemente a necessidade de uma base. A base é da ordem do direito porque aparece como norma, mas não se pode reduzir como e apenas listagem de conteúdo, como propôs a Escola sem Partido, pois esse ataque como redução a conteúdos “desloca, potencialmente, o jogo político na direção do fortalecimento das demandas neoliberais por accountability", (MACEDO, 2017a, p. 515). Se a Escola sem Partido tem tanto interesse na BNCC, no que ensinar, acredito que questionar a quem cabe esse direito de dizer o que ensinar, e onde, seja algo importante. É o que Macedo indaga ao trazer o pensamento de Aplle: "como funciona a normatividade a partir da qual se torna possível naturalizar que há um conhecimento mais válido para todos e que é possível defini-lo e torná-lo a base nacional para os currículos?”, (MACEDO, 2017a, p. 518). Aqui voltamos ao pensamento de Brown (2017) sobre a economização da vida pública, como um meio que a Escola sem Partido tem buscado, como inimigo (talvez), de uma força política ideológica específica. E se a base que antes não era currículo, então o que ela é?

Essa questão é feita também por Macedo em seu texto "A base é a base". E o currículo o que é? (MACEDO, 2018, p. 28). A sua tentativa de resposta é um dos meios de entender, nesse momento, não só o que é a base, como também pensar como ela continua produzindo sentidos após a sua implementação. Nesse texto Macedo usa a poesia de Stein "uma rosa é uma rosa" (MACEDO, 2018, p. 28) para mostrar que a nomeação da BNCC, "a base é a base”, segue 

MACEDO

reiterando seus significados. Com isso, traz a fala do ex-ministro da educação Renato Janine, “a educação é base", para questionar de que base o ministro se refere. Lopes (2019, p. 60-61), sugere que os esforços a uma base seja "um registro estabelecido como tendo um selo oficial de verdade, $[\ldots]$ esforços para tentar conter a tradução e impor uma leitura curricular como a única correta e obrigatória", por isso a pergunta de Macedo (2018) direciona a pensar sobre se ela contempla a educação que queremos propor aos estudantes. Se a ideia de ter a base é tornar útil o processo de fazer educação, ela é então "marquetizada, um bem a ser trocado no mercado futuro" (MACEDO, 2018, p. 28). Mas, se a afirmativa de que base não é currículo feita pelo ex-ministro, então questionar o que é o currículo, seja uma maneira de entender o seja a base. Não cabe aqui nomeações, porque na lógica em que venho operando, de perspectiva pósfundacional, o currículo não pode ser nomeado com uma coisa ou outra, pois ele acontece, é produzido diariamente, seja nas conversas de corredores escolares por alunos e professores, por conversas através de redes sociais, planejamento escolar, etc. Assim, não teria como dar conta de responder, porque não se estafam as possibilidades de sua produção.

Contudo, buscando apresentar uma resposta, Macedo (2018) afirma que "a BNCC seria, assim, currículo, mas não esgotaria as possibilidades de ser do currículo" (MACEDO, 2018, p. 29). Com isso, o que ela tenta expor, é que no campo clássico do currículo, que busca dar conta dos nomeados currículos formais, na BNCC, já está assumido pela própria literatura. Nesse texto, embora sua escrita não seja em uma aposta de currículo vívido ou em ação, acaba assumindo que se há esses currículos, os saberes que se diferem de mais aprendizagem, precisaria ir além do que eles perpassam. Seu convite é "uma chamada para que a escola se abra ao que não pode, nem muito menos deve, ser planejado, projetado e essa chamada anima um sentido de educação como subjetivação" (MACEDO, 2018, p. 29). Haja visto que o currículo prescrito, que é de alguma forma a proposta da BNCC, é implementado como currículo em ação. Apoiada em Ball segue sua defesa de que políticas como a base não trazem resultados de mais aprendizagem e justiça social, porque não há boa intenção quando um currículo tenta enquadrar, normatizar, "ditar o que o Outro deve ser" (MACEDO, 2018, p. 30). Então, "se a base é a base", inverter esse trocadilho por currículo também é a base, seria um meio de interpretar o que devemos fazer com ela, considerando que por ela já estamos contaminados. E se assim já estamos, o texto Fazendo a base virar realidade: competências e o germe da comparação, em que Macedo (2019) segue apostando que mesmo após a aprovação e implementação, a base "traz o gérmen do fascismo com suas certezas", (MACEDO, 2019, p. 

MACEDO

41), nos ajude nesse final de conversa complicada (PINAR, 2011). É o gérmen que traz certa homogeneização naquilo que deve ser ensinado e aprendido pelos alunos no contexto de sala de aula - uma tentativa de universalizar o ensino e a educação.

Em Derrida (2010), a busca por universalizar é de alguma forma um princípio de violência que tenta autorizar mais aprendizagem, mais justiça social, mais equidade. Por isso que Macedo, neste texto, coloca que como a BNCC já está aí para nós, "para se manter efetiva na significação da educação e da escolarização, ela tem que seguir reiterando os sentidos que instaura" (MACEDO, 2019, p. 41). Não há nada a perder ou a ganhar porque seus deslocamentos estão sempre em movimento. Tal ideia mostra os limites envolvidos na base, e que parece para ela, ser algo animador. Com isso volto a questão: e a base o que é? O MEC após assumir que a base não é currículo, articulou demandas que exigem que escolas construam seus currículos, seus projetos políticos pedagógicos articulados a ela. A problemática que se faz é, como então propor tal articulação fugindo da própria base? A estratégia é criar escapes de currículo com a base sem a base. Para Macedo (2019), olhar para as "entidades de terceiro setor" como um espaço por significação da base, permite entender como agora a base segue produzindo outros sentidos, ainda mais no atual governo de Jair Bolsonaro, que parece não ser uma preocupação, já que "no portal do MEC, não há praticamente nenhuma informação sobre a BNCC do Ensino Fundamental, sendo que as poucas notícias acessíveis datam de 2018" (MACEDO, 2019, p. 44). Enquanto isso, as secretarias de estados, juntamente com Undime e Consed, desde 2019, têm se mobilizado para continuidade da implementação da BNCC. Esse dado exposto por Macedo não denota a preocupação com a aprendizagem, e sim com "as avaliações de larga escala e a formação de professores” (MACEDO, 2019, p. 45), porque afinal, as escolas têm que apresentar bons resultados dentro das políticas públicas de estado.

Algo importante nesse texto, é a retomada de discussões já dadas em outras produções, como por exemplo, a influência de agentes privados na defesa e implementação da base, chamando a atenção para analisar os materiais produzidos por esses 'parceiros', já que fazem parte da política e da sua gestão; e o da página do Movimento pela Base Nacional Comum que elenca competências gerais, que provocou e ainda provoca debates na implementação. Todos eles na aposta de fazer a base virar realidade em que o termo competência não é só parte dos discursos, mas do próprio documento, que aparece em um sentido de economia (FOUCAULT, 2008). Esse termo não é algo deslocado porque "surge num momento de agudização da crise financeira internacional, quando a retórica da empregabilidade que a competência garantiria se 

MACEDO

desgastou", (MACEDO, 2019, p. 49). Por isso, a ideia de direitos universais, ampliação de mais aprendizagem, cidadania, equidade etc., aparecem como novas promessas de felicidade futura. O problema é se a ideia de competência passar por um discurso de sujeito mais competente e sujeito menos competente. Talvez aqui, fosse preciso trazer a ideia de bom e mau aluno. Afinal, quem é o sujeito competente? É o aluno que aparece com um perfil de bom aluno?

Para Macedo (2019, p. 52) “a comparação requer, e produz para existir, um genérico do sujeito, um nome sem face, o aluno competente (ou não)". Assim, não se pode dizer que ao trazer essas questões não esteja criando impasses em qualquer proposta do que seja educação, "porque sabemos, há muito, que não é possível fazer educação (integral) sem gente de corpo e alma" (MACEDO, 2019, p. 52). Tal fala leva Macedo a finalizar o texto fazendo a seguinte questão: “e se os benchmarks fossem outros?”, (MACEDO, 2019, p. 52). Essa pergunta é feita em razão de que "a força simbólica de tais benchmarks está explicitada na página do Movimento por um link específico para as experiências internacionais”, (MACEDO, 2019, p. 53), e nas políticas de avaliação. Talvez os dados nos mostrem, de que não precisamos de uma base, como já vem mostrando, pois afinal, “A base é escolas com boas condições materiais e de infraestrutura. Isso é base, o que tem sido chamado de Base é a pretensão de definir o horizonte logo ali onde os olhos do controle podem alcançar”, (MACEDO, 2019, p. 54).

\section{Algumas considerações}

A produção de Macedo entorno da base tem buscado discutir a política educacional e de currículo como uma luta de controle de aprendizagens e educação, uma luta de controle de processos de significação. A sua preocupação é trazer articulações de que currículos centralizados em nível nacional não são alterativas para melhorar a qualidade do ensino, como propõe a BNCC. Por isso, em seus escritos tem documentado experiências de outros países que optou por currículos centralizados; e como agentes públicos e privados têm interferido nas políticas de educação em nome de um melhor resultado por meio de testagens avaliativas. Há um caminho a ser feito, diz Macedo em seus textos, que é apostar no imprevisível, no modo de fazer educação, porque afinal, "não se educa sem levar a imprevisibilidade a sério, porque é nela que o outro surge como outro e não há educação sem sujeito", (MACEDO, 2019a, p.10). A BNCC está para nós, como ela coloca, ela produz seus sentidos, só que sempre em deslocamento. Não podemos rasgá-la, jogá-la fora, mas podemos arriscar produzir novas 

MACEDO

significações, inclusive naquilo que é dissenso a base, com todas as angústias que nos perseguem. Este é o convite de Macedo em que me junto por mais educação pública, democrática e de qualidade!

\section{REFERÊNCIAS}

BROWN, W. El Pueblo Sin Atributos La Secreta Revolución Del Neoliberalismo. Editora: Malpaso, 2017.

BUTLER, J. Corpos em aliança e a política das ruas: notas para uma teoria performativa da assembleia. Rio de Janeiro: Civilização Brasileira, 2018.

DERRIDA, J. Salvo o nome. Trad. Nícia Adan Bonatti. Campinas: Papirus Editora, 1995.

DERRIDA, J. Força de Lei: o fundamento místico da autoridade. 2 ed. São Paulo: Editora WMF Martins Fontes, 2010.

FOUCAULT, M. Nascimento da biopolítica: curso dado no Collège de France (1978-1979). São Paulo: Martins Fontes, 2008.

HYPOLITO, A. M. BNCC, Agenda Global E Formação Docente. Retratos da Escola, Brasília, v. 13, n. 25, p. 187-201, 2019.

LOPES, A. C. Normatividade e intervenção política: em defesa de um investimento radical. In: LOPES, A. C; MENDONÇA. D. (Org.). A Teoria do Discurso de Ernesto Laclau: ensaios críticos e entrevistas. São Paulo: Annablume, p. 117-147, 2015.

LOPES, A. C. Itinerários formativos na BNCC do Ensino Médio: identificações docentes e projetos de vida juvenis. Retratos da Escola, Brasília, v. 13, n. 25, jan./mai., p. 59-75, 2019.

MACEDO, E. Base nacional curricular comum: novas formas de sociabilidade produzindo sentidos para educação. Revista e-Curriculum, São Paulo, v. 12, n. 03, out./dez. p.1530 1555, 2014.

MACEDO, E. Base nacional comum para currículos: direitos de aprendizagem e desenvolvimento para quem? Educação e Sociedade, Campinas, v. 36, nº ${ }^{\circ}$ 133, p. 891-908, 2015.

MACEDO, E. Base nacional curricular comum: a falsa oposição entre conhecimento para fazer algo e conhecimento em si. Educação em Revista, Belo Horizont, v.32, n.02, p. 45-67, 2016.

MACEDO, E. Mas a escolar não tem que ensinar?: Conhecimento, reconhecimento e alteridade na teoria do currículo. Currículo sem fronteiras, v. 17, n. 3, set./dez., p. 539-554, 2017. 

MACEDO

MACEDO, E. As demandas conservadoras do movimento escola sem partido e a base nacional curricular comum. Educação e Sociedade, Campinas, v. 38, nº 139, p.507-524, 2017 a.

MACEDO, E. "A base é a base". E o currículo o que é? In: AGUIAR, M. A. S.; DOURADO, L. F. A BNCC na contramão do PNE 2014-2024: avaliação e perspectivas. [Livro Eletrônico]. - Recife: ANPAE, p. 28-33, 2018.

MACEDO, E. Fazendo a Base virar realidade: competências e o germe da comparação. Revista Retratos da Escola, Brasília, v. 13, n. 25, jan./mai. p. 39-58, 2019.

MACEDO, E. Prefácio. In: SILVA, F. C. T; FILHA, C. X. Conhecimento em disputa na base nacional comum curricular. Campo Grande: MS: Ed Oeste, p. 09-21, 2019a.

PINAR, W. F. The character of curriculum studies: bildung, currere, and the recurring of the subject. New York: Palgrave Macmillan, 2011.

PRICE, T. Comum pra quem? Revista e-curriculum, São Paulo, v. 12, n. 3, p. 1614-1633, 2014.

Notas

i Agência financiadora: Fundação Carlos Chagas Filho de Amparo à Pesquisa do Estado do Rio de Janeiro FAPERJ. 